\title{
Appraisal of Noise Level Dissemination Surrounding Mining and Industrial Areas of Keonjhar, Odisha: a Comprehensive Approach Using Noise Mapping
}

\author{
Satish K. LOKHANDE, Satyajeet A. DHAWALE, Samir S. PATHAK, \\ Rakesh GAUTAM, Mohindra C. JAIN, Ghanshyam L. BODHE \\ Analytical Instruments Division \\ CSIR - National Environmental Engineering Research Institute \\ Nehru Marg, Nagpur, Maharashtra - 440020 India; e-mail: s_lokhande@neeri.res.in
}

(received November 30, 2016; accepted April 25, 2017)

\begin{abstract}
Noise mapping is a well-established practice among the European nations, and it has been follow for almost two decades. Recently, as per guidelines of the Directorate General of Mines Safety (DGMS), India, noise mapping has been made mandatory in the mining expanses. This study is an effort to map the noise levels in nearby areas of mines in the northern Keonjhar district. The motive of this study is to quantify the existing A-weighted time-average sound level $\left(L_{\mathrm{Aeq}, T}\right)$ in the study area to probe its effects on the human dwellings and noise sensitive areas with the probability of future development of the mines, roads, and industrial and commercial zone. The $L_{\text {Aeq, }} T$ was measured at 39 identified locations, including industrial, commercial, residential, and sensitive zones, 15 open cast mines, 3 major highways, and 3 haulage roads. With the utilisation of Predictor LimA Software and other GIS tools, the worked out data is mapped and noise contours are developed for the visualisation and identification of the extent and distribution of sound levels across the study area. This investigation discloses that the present noise level at $60 \%$ of the locations in silence and residential zone exposed to significantly high noise levels surpasses the prescribed limit of Central Pollution Control Board (CPCB), India. The observed day and night time $L_{\text {Aeq, } T}$ level of both zones ranged between $43.2-62.2 \mathrm{~dB}(\mathrm{~A})$ and $30.5-53.4 \mathrm{~dB}(\mathrm{~A})$, respectively, whereas, the average $L_{\mathrm{dn}}$ values vary between 32.7 and $51.2 \mathrm{~dB}(\mathrm{~A})$. The extensive mobility of heavy vehicles adjoining the sensitive areas and a nearby plethora of open cast mines is the leading cause of exceeded noise levels. The study divulges that the delicate establishments like schools and hospitals are susceptible to high noise levels throughout the day and night. A correlation between observed and software predicted values gives $R^{2}$ of 0.605 for $L_{\mathrm{d}}, 0.217$ for $L_{\mathrm{n}}$, and 0.524 for $L_{\mathrm{dn}}$. Finally, the mitigation measure is proposed and demonstrated using a contour map showing a significant reduction in the noise levels by $0-5.3 \mathrm{~dB}(\mathrm{~A})$.
\end{abstract}

Keywords: noise mapping; noise prediction; predictor LimA; mining, GIS.

\section{Introduction}

To meet the exponentially increasing demands of natural minerals from all over the world, their production has been rapidly increased over a period of time, due to introducing modern and larger machinery (such as continuous miner, mine trucks, bulldozer, drilling machines) with advanced technology. The increase of such types of machinery also given rise to heavy road transportation and enormous raise of noise levels.

As the miners dig shallower into the earth, the machinery in the pits generates a harsh, unbearable noise that annoys not only the mining area workers but also nearby rural and urban settlements. Continuous exposure to noise for years leads to irreversible damage to ears and may cause Noise-Induced Hearing Loss (NIHL) which is the most hazardous and common disease in mining occupation (BAUER, KOHLER, 2000).

Odisha is acknowledged as the mineral-rich place, where natural resources are available in 25 districts out of 30 . The top five regions, where mining actions are carried out on a massive scale, includes $31.28 \%$ in Keonjhar, 20.03\% in Sundergarh, 10.24\% in Angul fol- 
lowed by $8.87 \%$ in Jharsuguda, and $6.3 \%$ in Koraput, the rest of the districts have the lease area less than 5\% (Murthy, RAO, 2006). Unfortunately, mining has made an enormous impact on the environment and affected the suburbs of many rural areas in the form of dust, road traffic noise, vibrations, etc.

Additionally, the massive transportation has also contaminated the surrounding of the Keonjhar, which is subsequent to industrialisation in inducing irretrievable destruction to the environment. In addition, the number of vehicles in Odisha has upsurged by $112 \%$ between 2007-2008 and 2013-14 (OES, 2014-15), which is becoming a key factor in increased noise levels. The origin of such sound is numerous and varied according to the type of source, however, the most substantial is from road traffic.

Finally, the noise mapping practices concern traffic, industry, aircraft, and railways, and especially mining noise pollution performed on a very low scale in India. However, these methods are frequently used in developed countries like Australia, China, USA and in many European nations. The assessment of noise pollution using noise mapping is an absolutely new research area in India, especially in the mining industry and nearby mining regions. This study aims to quantify and map the present $L_{\text {Aeq, } T}$ in the northern Keonjhar district to probe its effects on the residential and sensitive zones with the probability of future expansion of the mines, road traffic, and industrial and commercial zones in the area.

\section{Literature review}

The hasty growth of heavy industries and urbanisation of towns has put a severe impact on the environmental noise pollution across the world. A study was conducted by (Doygun, Gurun, 2007) to quantify the noise pollution from urban traffic in the city of Kahramanmaraş, Turkey. They developed a day $\left(L_{\mathrm{d}}\right)$, night $\left(L_{\mathrm{n}}\right)$, and day-night $\left(L_{\mathrm{dn}}\right)$ contour noise maps using an ordinary co-kriging in ArcGIS 9.1 software and the results show that the sound exposure levels are exceeding the norm in some areas due to lack of maintenance of privately-owned outdated transportation vehicles.

Another work, carried out by (BANERJEE et al., 2009) from 2006 to 2008 in Asansol, a metropolitan city of West Bengal, India, which involves the assessment and measuring of temporal road traffic noise distribution in the urban area, shows that the noise from highways is relatively higher as compared to local topography. Assessment and analysis of noise exposure levels from heavy machinery in a chromite mine of Odisha, India, is discussed in (KerketTa et al., 2013). This study shows that most of the noise is generated from the heavy vehicle (Pay Loader) during the morning hours.
Furthermore, for noise mapping (KALAISELVI, RAMACHANDRAIAH, 2010) had used a computer simulation model (Soundplan) for noise prediction of heterogeneous traffic of Chennai city in India. In this work, they developed a noise prediction model for heterogeneous traffic conditions of Chennai city.

Additionally, several previous studies have revealed that noise mapping is an ideal approach for enlisting noise level mitigation strategies. For example (KIM et al., 2008), used noise mapping to predict the noise distribution of construction site and road traffic noise in the area of Korea during construction and after it's been constructed. From this study it was concluded that noise maps could be used as noise mitigation document at the time of construction of projects and to regulate road traffic noise in urban areas.

\section{Study area}

The district of Keonjhar is situated in the northern part of Odisha in India, with an area of $8240 \mathrm{~km}^{2}$; it lies between $21^{\circ} 1^{\prime} \mathrm{N}$ to $22^{\circ} 10^{\prime} \mathrm{N}$ latitude and $85^{\circ} 11^{\prime} \mathrm{E}$ to $86^{\circ} 22^{\prime} \mathrm{E}$ longitude. According to the report of Odisha economic survey 2014-2015, the iron ore deposit of Keonjhar district is approximated as more than 1000 million tonnes. The national highways NH49, NH520, and $\mathrm{NH} 20$ are the major roads of the district utilised for transportation of minerals and general public use.

The study area (Fig. 1) includes the measurement of $L_{\text {Aeq, } T}$ level at nine industrial, seven commercial, six residential, seventeen silence zones, and fifteen mining locations. Human dwellings and sensitive establishments are situated near the highway, and they are also influenced by the high noise levels of heavy vehicles. Hence, noise levels are also measured at three major highways, viz. NH520, NH20, and SH-10B, which are connected with two haulage roads from which maximum mining conveyance takes place (Fig. 1).

\section{Method and material}

Figure 2 demonstrates the methodology followed during the research. The complete assessment has three stages, where the first stage consists of four steps for identification of monitoring location, the second stage implicates the data entry of raw data into Excel sheets and calculation of noise identifiers like equivalent sound levels during the day $\left(L_{\mathrm{d}}\right)$, equivalent noise levels during the night $\left(L_{\mathrm{n}}\right)$, day-night average noise levels $\left(L_{\mathrm{dn}}\right)$, and sound power level $\left(L_{\mathrm{w}}\right)$, and the last stage involves utilisation of soft - computing techniques for the mapping of an entire study area.

Equipment containing precision-grade Sound Level Meter (SLM) CK: 172B Optimus Green (Cirrus, UK) with Fast, A-Weighted Sound Level response mode (LAF) and having data logging of $0.125 \mathrm{~s}$ (125 ms) time interval was used for field measurements. The 


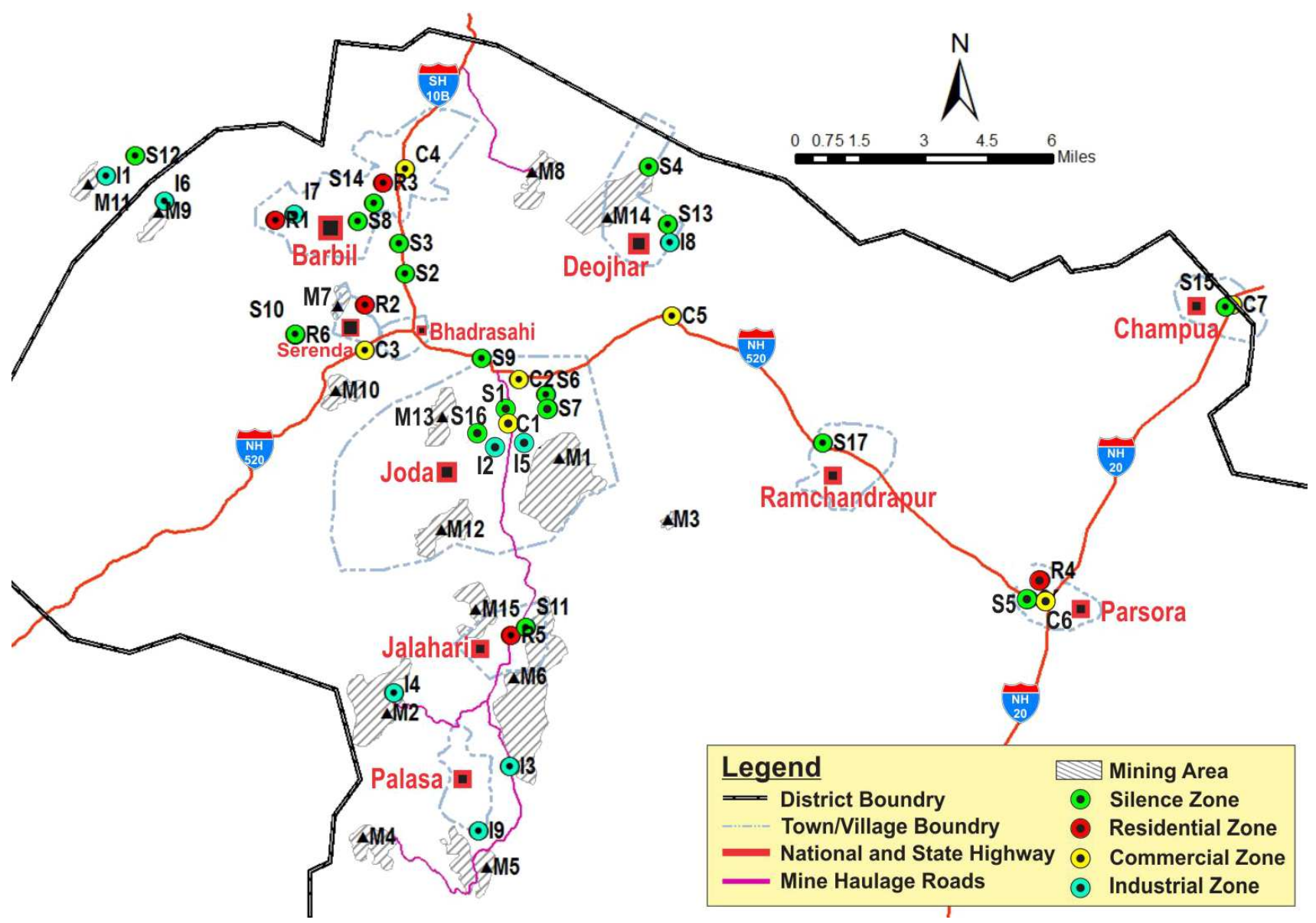

Fig. 1. Study Area in Northern Keonjhar District.

\begin{tabular}{|c|}
\hline Stage I : Zone Identification and Monitoring \\
\hline Step 1: Identifying the 4 zone in the Keonjhar district \\
\hline Step 2: Identifying the measuring location in the selected zone \\
\hline Step 3: Measuring the Sound Exposer Level $\left(\mathrm{L}_{\mathrm{AE}}\right)$ for $1 \mathrm{hr}$ for each location \\
\hline Step 4: Collecting physical parameter (Temp., RH, Lat. Long.) \\
\hline Stage II : Data Entry and Calculation \\
\hline Step 5: Transferring the raw data into Excel sheet \\
\hline Step 6: Calculating the $L_{d}, L_{n}$ and $L_{d n}$ \\
\hline Step 7: Calculation of Sound Power $\left(L_{w}\right)$ \\
\hline Stage III : Mapping \\
\hline Step 8: Marking locations in Google Earth and making shape file \\
\hline Step 9: Importing *.kml file into Predictor LimA \\
\hline $\begin{array}{l}\text { Step 10: Selecting noise source, defining grid and } \\
\text { giving calculated } L_{w} \text { for each location }\end{array}$ \\
\hline Step 11: Generating 2D contours maps using Predictor LimA \\
\hline
\end{tabular}

Fig. 2. Methodology. definitive range of equipment for one-third octave band filter with frequency and measuring level is of $20 \mathrm{~Hz}$ to $20 \mathrm{kHz}$ and 20-140 dB, respectively (CR, 2016).

The gadget, sound level meter placed on a tripod with the microphone pointed at the supposed noise source and positioned away from the road. The $L_{\text {Aeq, } T}$ were taken for 1 hour $\left(L_{\text {Aeq, } 1}\right)$ at each location in the day and night time to obtain $L_{\mathrm{d}}$ and $L_{\mathrm{n}}$. A short-term noise monitoring strategy was adopted in this work, as it gives a reliable accuracy levels as compared to long-term monitoring and a better technique for noise mapping of larger areas (GARG et al., 2015). These noise levels are utilised to compute the $L_{\mathrm{dn}}$ values, which is a 24 hrs day-night average noise level, where extra $10 \mathrm{~dB}(\mathrm{~A})$ is contributed during the night time as a mark of penalisation. The expression for $L_{\mathrm{d}}, L_{\mathrm{n}}$, and $L_{\mathrm{dn}}$ is given in Eqs. (1), (2), and (3) (PRAsCEviC et al., 2014; BARron, 2002)

$$
\begin{aligned}
& L_{\mathrm{d}}=10 \log _{10} \frac{1}{16} \sum_{i=1}^{n} t \cdot 10^{(0.1) \cdot\left(L_{\text {eqi }}\right)}, \\
& L_{\mathrm{n}}=10 \log _{10} \frac{1}{8} \sum_{i=1}^{n} t \cdot 10^{(0.1) \cdot\left(L_{\text {eqi }}\right)}
\end{aligned}
$$




$$
\begin{aligned}
L_{\mathrm{dn}}[\mathrm{dB}(\mathrm{A})]= & 10 \cdot \log _{10} \\
& \cdot\left[\frac{16}{24}\left(10^{\frac{L_{\mathrm{d}}}{10}}\right)+\frac{8}{24}\left(10^{\frac{\left(L_{\mathrm{n}}+10\right)}{10}}\right)\right],
\end{aligned}
$$

where $L_{\mathrm{eq}}$ is the average equivalent noise level for the duration of 1 hour; $t$ is the time of duration of the measurement ( $1 \mathrm{hr}$ in this case)

The obtained sound pressure levels (SPL) for each reading were converted into their equivalent $L_{\mathrm{w}}$ for different one-third octave band frequencies using formula (4) (WhitAKer, Benson, 2001)

$$
L_{\mathrm{w}}=L_{\mathrm{p}}-10 \log \left(\frac{Q}{4 \pi r^{2}}\right)
$$

where $L_{\mathrm{w}}$ is the sound power level in $\mathrm{dB}(\mathrm{A}) ; L_{p}$ is $\mathrm{SPL}$ in $\mathrm{dB}(\mathrm{A}) ; Q$ is the directivity factor which is 1 in each case; $r$ is the distance from the source which is $1.5 \mathrm{~m}$ in every case.

\section{Noise mapping}

The intent of this study was to assess and inspect the impact of noise engendered due to mining activity, industrial and commercial activities, and mining conveyance on highways on nearby residential areas and sensitive establishments. Noise mapping is an effective assessment method in urban regions and proves an advisable document in planning and noise mitigation measures. Noise mapping is implemented with the help of Predictor LimA (LimA, 2016) software (Type 7810,11v), it defines the spatial distribution of noise levels and produces an adequate visualisation of the noise dispersals in areas which are sensitive to noise. This prediction tool uses the ISO 9613 calculation method to predict noise, which is the primary calculation method in this work. The software predicts attenuation of sound waves as they originated from the sound source and shows how they would behave if influenced by geographical and meteorological factors in the environment. This soft computing technique ratifies to be an ideal tool for executing noise impact assessments in urban and rural settings.

The process of noise mapping initiates with a marking of the selected locations in the Google Earth and then importing the map into the Prediction software in the suitable file format. A universal coordinate system was used for integration of the Google Earth map with Geo-referenced data such as latitude and longitude of the selected noise sources. Then all the sampling locations as a point, line, and area sources were marked on the workspace of mapping software by keeping the map of Keonjhar district in the background. The sources of noise from all identified industrial and commercial zones were treated as point sources, mining areas as an area source, whereas highways as line source, for noise prediction. Then the calculated $L_{\mathrm{w}}$ for each one third-octave band frequency is given as input for each point source location as it only accepts the $L_{\mathrm{w}}$ of the noise sources for calculation of propagation of sound waves. For calculation of the noise levels, the contours were generated on the $200 \times 200 \mathrm{~m}$ grid, and each grid point is at the height of $4 \mathrm{~m}$, acting as receiver points.

The propagation of sound waves is easily affected due to a complex geographical topology of open-cast mining, causing frequent reflection or absorption of sound waves. Such meteorological factors yield in superfluous effects on the propagation pattern of sound waves and make the noise assessment exercise so rigorous and hence the mapping becomes a complex task at all adjacent regions of mines.

\section{Results and discussion}

\subsection{Assessment of noise descriptors}

Some fallouts clinched from observations, and clarifications about them are specified in this segment. The noise pollution directive and control guidelines, as recommended by the CPCB, India (CPCB, 2010) shown in Table 1, are followed to assess the noise levels for $L_{\mathrm{d}}$ and $L_{\mathrm{n}}$.

Table 1. Ambient noise quality standards in respect of noise (as recommended by CPCB).

\begin{tabular}{|l|c|c|}
\hline \multirow{2}{*}{ Category of area } & \multicolumn{2}{|c|}{ Noise level in $L_{\text {eq }}[\mathrm{dB}(\mathrm{A})]$} \\
\cline { 2 - 3 } & Day time & Night time \\
\hline Industries area & 75 & 70 \\
\hline Commercial area & 65 & 55 \\
\hline Residential area & 55 & 45 \\
\hline Silence zone & 50 & 40 \\
\hline
\end{tabular}

Table 2 shows the observed $L_{\text {Aeq, }} 1 \mathrm{hr}$ levels of the zones identified as noise source along with their calculated $L_{\mathrm{d}}, L_{\mathrm{n}}$, and $L_{\mathrm{dn}}$ values. The sources of noise include measurement of noise levels of industrial and commercial zones and mining areas.

In view of industries, there are numerous manufacturing units in this region that include iron, steel, power loom, stone crushing, and other allied industries. The noise levels of these manufacturing industries vary from 64.2 to $73.4 \mathrm{~dB}(\mathrm{~A})$ and 55.2 to $64.4 \mathrm{~dB}(\mathrm{~A})$ during the day and in the night time, respectively. The noise levels of these locations are not exceeding the prescribed limits of CPCB.

The commercial and business organisations are of several categories including individual establishments, a group of shops and assigned vicinity in the form of supermarkets, shopping malls, etc. The noise levels in these regions varied between 62.2 to $72.7 \mathrm{~dB}(\mathrm{~A})$ and 52.6 to $55.6 \mathrm{~dB}(\mathrm{~A})$ during the day and in the night time. The highest noise level $(72.7 \mathrm{~dB}(\mathrm{~A}))$ was ob- 
Table 2. Average noise levels of considered noise sources.

\begin{tabular}{|c|c|c|c|c|c|c|}
\hline \multirow{2}{*}{ Sampling zone } & \multirow{2}{*}{ Location ID in map } & \multicolumn{2}{|c|}{ Day $(6$ am - 10 pm) } & \multicolumn{2}{|c|}{ Night $(10 \mathrm{pm}-6 \mathrm{am})$} & \multirow{2}{*}{$\frac{\text { Day-Night }(24 \mathrm{hrs})}{L_{\mathrm{dn}}}$} \\
\hline & & $L_{\text {Aeq, } 1}$ & $L_{\mathrm{d}}$ & $L_{\text {Aeq, } 1}$ & $L_{\mathrm{n}}$ & \\
\hline \multirow{9}{*}{ Industrial zone } & I1 & 68.2 & 56.2 & 55.2 & 46.2 & 56.2 \\
\hline & $\mathrm{I} 2$ & 67.3 & 55.3 & 56.7 & 47.7 & 56.2 \\
\hline & I3 & 68.4 & 56.4 & 56.8 & 47.8 & 56.9 \\
\hline & $\mathrm{I} 4$ & 73.4 & 61.4 & 58.3 & 49.3 & 60.8 \\
\hline & I5 & 64.2 & 52.2 & 55.4 & 46.4 & 54.0 \\
\hline & I6 & 71.5 & 59.5 & 61.6 & 52.6 & 60.8 \\
\hline & I7 & 67.4 & 55.4 & 58.8 & 49.8 & 57.4 \\
\hline & I8 & 66.9 & 54.9 & 64.4 & 55.4 & 61.3 \\
\hline & I9 & 67.5 & 55.5 & 57.3 & 48.3 & 56.6 \\
\hline \multirow{7}{*}{ Commercial zone } & $\mathrm{C} 1$ & 62.2 & 50.2 & 54.2 & 45.2 & 52.5 \\
\hline & $\mathrm{C} 2$ & 64.8 & 52.8 & 52.6 & 43.6 & 53.0 \\
\hline & C3 & 66.4 & 54.4 & 53.6 & 44.6 & 54.4 \\
\hline & $\mathrm{C} 4$ & 69.7 & 57.7 & 54.4 & 45.4 & 57.0 \\
\hline & C5 & 69.5 & 57.5 & 53.4 & 44.4 & 56.7 \\
\hline & C6 & 68.9 & 56.9 & 54.9 & 45.9 & 56.6 \\
\hline & $\mathrm{C} 7$ & 72.7 & 60.7 & 55.6 & 46.6 & 59.7 \\
\hline \multirow{15}{*}{ Mines } & M1 & 94.8 & 82.7 & 91.3 & 82.3 & 88.4 \\
\hline & M2 & 93.9 & 81.9 & 89.0 & 80.0 & 86.4 \\
\hline & M3 & 91.3 & 79.2 & 84.2 & 75.2 & 82.2 \\
\hline & M4 & 116.2 & 104.2 & 109.5 & 100.5 & 107.4 \\
\hline & M5 & 97.6 & 85.5 & 95.5 & 86.5 & 92.3 \\
\hline & M6 & 114.4 & 102.3 & 112.7 & 103.6 & 109.4 \\
\hline & M7 & 115.0 & 103.0 & 109.6 & 100.6 & 107.1 \\
\hline & M8 & 117.0 & 105.0 & 120.5 & 111.5 & 116.9 \\
\hline & M9 & 93.2 & 81.2 & 88.5 & 79.4 & 85.8 \\
\hline & M10 & 114.0 & 101.9 & 109.7 & 100.6 & 106.9 \\
\hline & M11 & 91.1 & 79.1 & 97.1 & 88.1 & 93.4 \\
\hline & M12 & 92.9 & 80.8 & 89.2 & 80.2 & 86.3 \\
\hline & M13 & 115.9 & 103.9 & 110.2 & 101.2 & 107.8 \\
\hline & M14 & 112.9 & 100.9 & 108.7 & 99.6 & 105.9 \\
\hline & M15 & 92.4 & 80.4 & 87.0 & 78.0 & 84.5 \\
\hline
\end{tabular}

served during the day period in the Champua marketplace due to the substantial movement of different types of vehicles on NH-20 passing closely from the sensitive zones. The noise levels in five locations (i.e., C3-C7) are exceeding the prescribed limits of CPCB. These surpassing noise levels may occur because during the day time the extra traffic of private vehicles for activities such as shopping appears, resulting in high traffic blockages and more sound emissions. On the other hand, though the measurements of the night time are below the prescribed limits of CPCB except for $\mathrm{C} 7$, on the contrary, all the readings are above $52.6 \mathrm{~dB}(\mathrm{~A})$. The insufficiency of appropriate parking area proximate to market zone besides, uneffective management of the traffic scheme generates severe noise throughout the day and particularly in peak hours. The intermittent blaring of honking is also responsible for annoyance in the entire area.

Additionally, the average noise observed in the 15 mining areas varies between 91.1 to $117.0 \mathrm{~dB}(\mathrm{~A})$ during the day time and 84.2 to $120.5 \mathrm{~dB}(\mathrm{~A})$ through the night time. Most of the noise in the mining area is due to heavy-duty machinery like rock breakers, drill machines, dumpers, dozers, etc.

Furthermore, the Environmental Protection Agency (EPA), USA has suggested guidelines for indoor and outdoor day-night sound levels for activity interference and hearing loss considerations (EPA, 1974). Since the $\mathrm{CPCB}$, India does not have any permissible limits for $L_{\mathrm{dn}}$, the values of those computed in this study are 
compared with allowable limits suggested by EPA, as shown in Table 3.

Table 3. Simplified version of permissible limits of day-night average equivalent sound levels (as recommended by EPA).

\begin{tabular}{|l|c|c|}
\hline \multirow{2}{*}{ Category of area } & \multicolumn{2}{|c|}{ Permissible limits of $L_{\mathrm{dn}}$ as per EPA } \\
\cline { 2 - 3 } & Indoor $[\mathrm{dB}(\mathrm{A})]$ & Outdoor $[\mathrm{dB}(\mathrm{A})]$ \\
\hline Industries area & 70 & 70 \\
\hline Commercial area & 70 & 70 \\
\hline Residential area & 45 & 55 \\
\hline Silence zone & 45 & 55 \\
\hline
\end{tabular}

Therefore, from Table 2, the maximal and minimal day-night average noise levels in the commercial zone vary from $52.5 \mathrm{~dB}(\mathrm{~A})$ to $59.7 \mathrm{~dB}(\mathrm{~A})$; and that of industrial zone measured between $54.0 \mathrm{~dB}(\mathrm{~A})$ and $61.3 \mathrm{~dB}(\mathrm{~A})$, which is below the EPA limits. Subsequently, the day-night equivalent noise level for the mining zone ranged from 82.2 to $116.9 \mathrm{~dB}(\mathrm{~A})$, which is undoubtedly exceeding the EPA guidelines.

Noise measurements appraising the impact of noise induced from road traffic on the residential and sensitive establishments were carried out on highways and other arterial roads. Table 4 shows the $L_{\text {Aeq, } T}$ measurement of the major highway and haulage road used for transportation. As heavy vehicles are the major source of noise in urban as well as in rural areas, here only the traffic from heavy vehicles was considered for noise prediction purpose.

The predicted noise contour maps of the study area are generated to visualise the effect of annoying noise levels instigated from mining, road traffic, commercial
Table 4. Observed noise levels on highways and haulage road.

\begin{tabular}{|l|c|c|c|}
\hline $\begin{array}{l}\text { Highway } \\
\text { name }\end{array}$ & $\begin{array}{c}\text { Heavy vehicle } \\
\text { flow } \\
\text { (day time) }\end{array}$ & $\begin{array}{c}\text { Heavy vehicle } \\
\text { flow } \\
\text { (night time) }\end{array}$ & $L_{\text {Aeq, } 1}$ \\
\hline NH-520 & 5632 & 2816 & 78.5 \\
\hline SH-10B & 1664 & 832 & 59.2 \\
\hline NH-20 & 2112 & 1056 & 75.8 \\
\hline $\begin{array}{l}\text { Mine haulage } \\
\text { road-1 }\end{array}$ & 1632 & 816 & 71.1 \\
\hline $\begin{array}{l}\text { Mine haulage } \\
\text { road-2 }\end{array}$ & 2496 & 1248 & 61.3 \\
\hline $\begin{array}{l}\text { Mine haulage } \\
\text { road-3 }\end{array}$ & 480 & 240 & 61.9 \\
\hline
\end{tabular}

and industrial activities on the human dwellings and sensitive establishments illustrated in Figs. 3, 4, and 5. Different colour codes were used to represent various noise levels. Noise levels ranging from 50 to $80 \mathrm{~dB}(\mathrm{~A})$ are indicated with three shades of violet, as they exceed the CPCB limits. Noise levels between 20 to $50 \mathrm{~dB}(\mathrm{~A})$ are represented with yellow, orange, and red shade as those areas are within the limits of $\mathrm{CPCB}$, and noise levels between 0 to $20 \mathrm{~dB}(\mathrm{~A})$ are shown with 2 bands of green.

Figures 3 and 4 depict that 4 locations (S1, S14, $\mathrm{S} 15, \mathrm{~S} 16)$ during the day time and 6 locations (S1, S4, S7, S12, S13, S16) during the night time of the sensitive zone are exposed to high noise levels and are exceeding the noise limits permitted by CPCB. Whereas, Fig. 5 illustrates the overall scenario of the day-night noise levels where only 2 locations from the silence zone

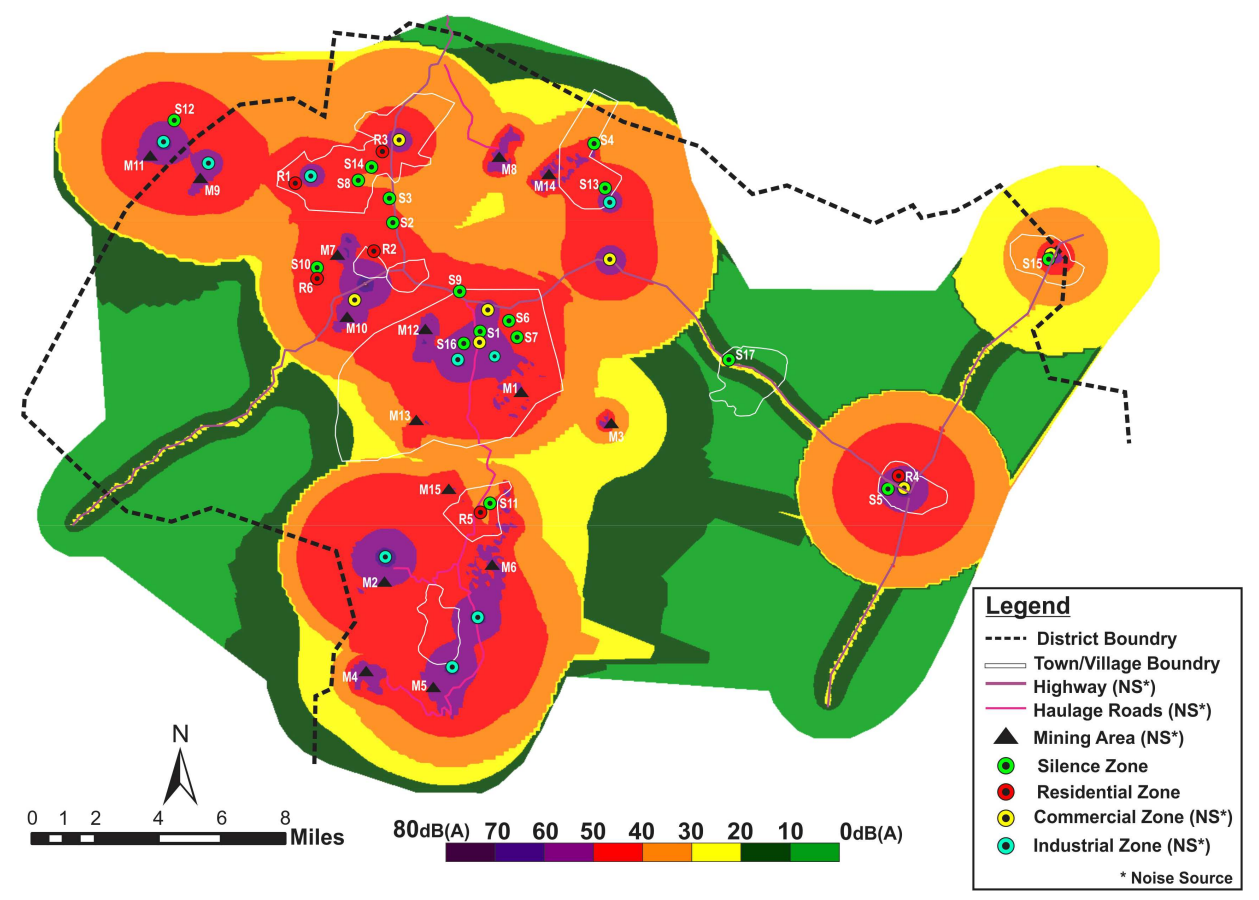

Fig. 3. Noise contour map representing predicted noise index during the day time. 


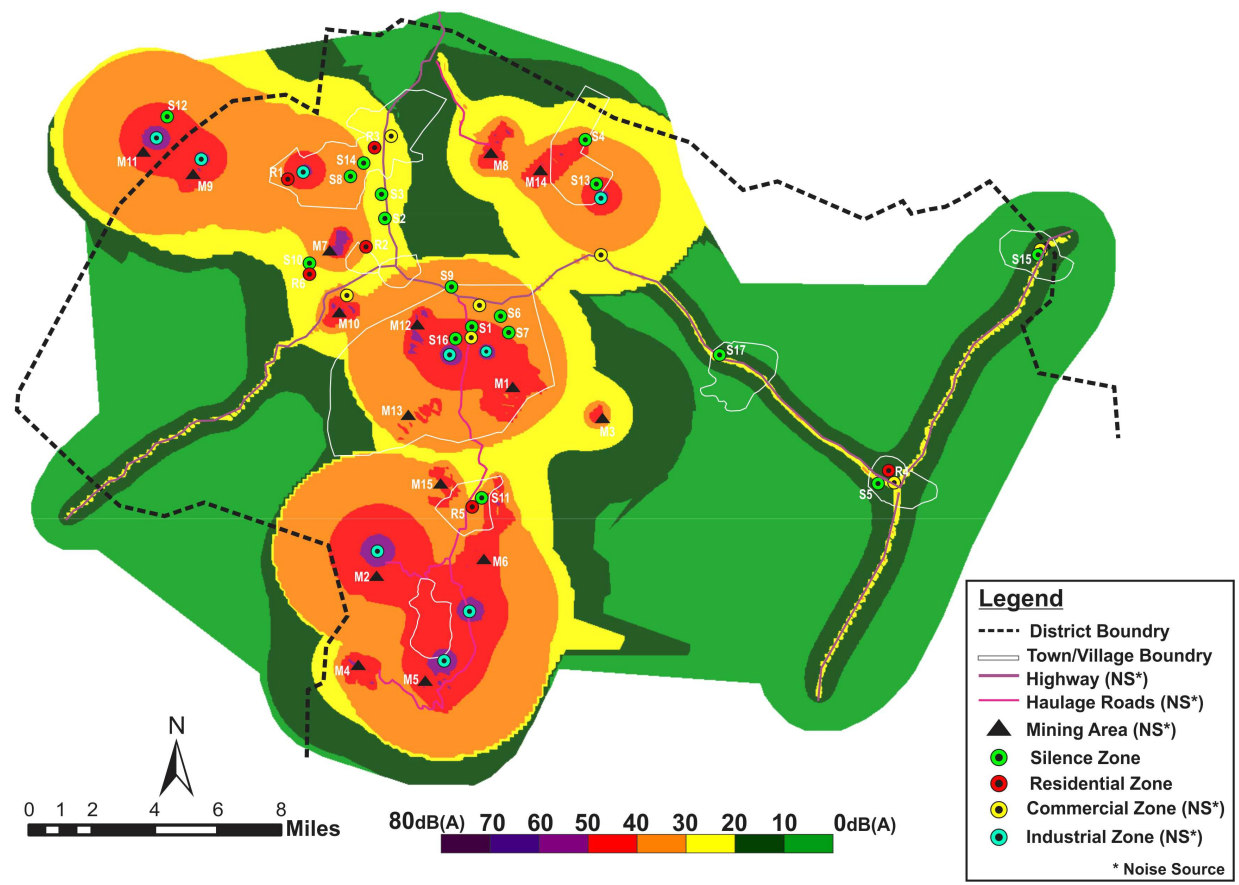

Fig. 4. Noise contour map representing predicted noise index during night time.

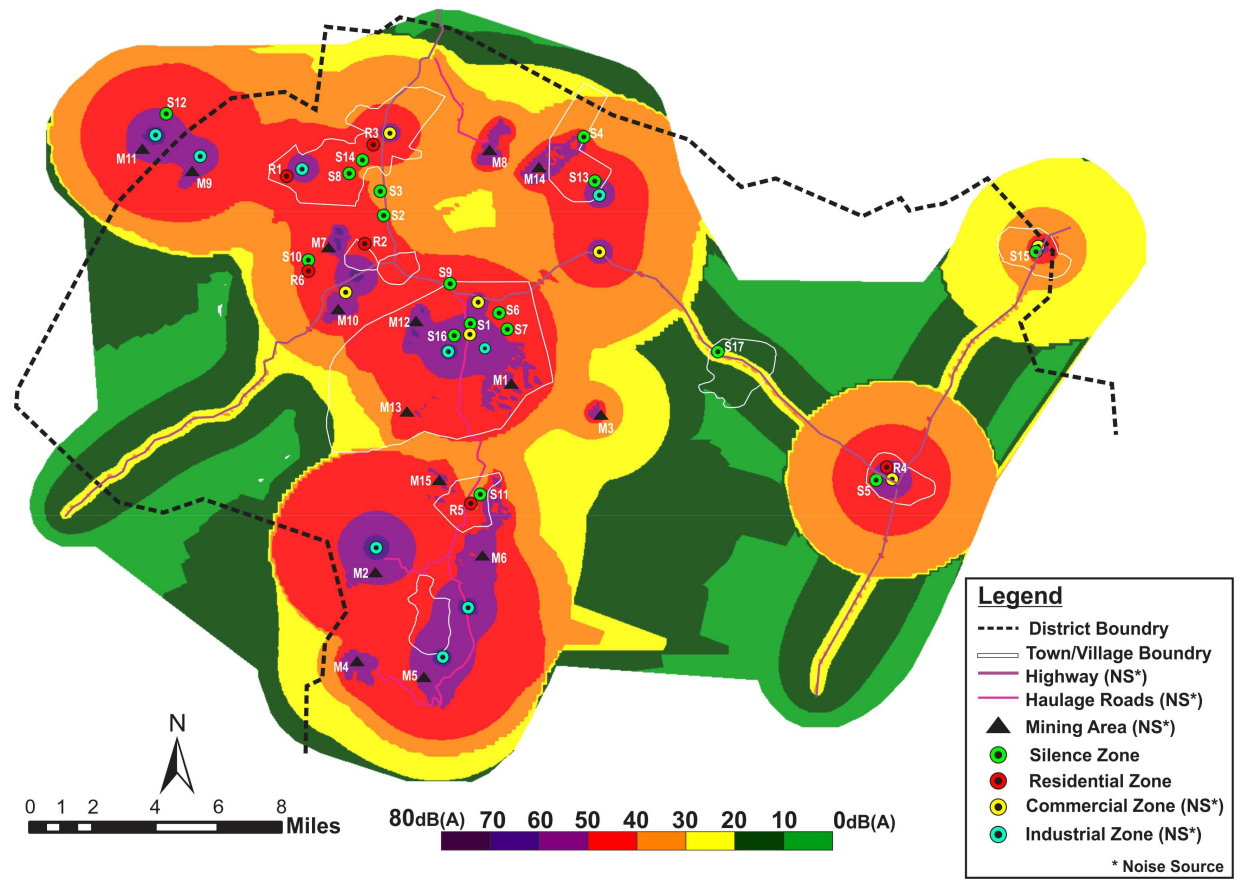

Fig. 5. Noise contour map representing predicted noise index during the day-night time.

(S1 and S16) are exposed to high noise levels and are exceeding the EPA $L_{\mathrm{dn}}$ permissible limits. In contrast, the rest of the $L_{\mathrm{dn}}$ measurements are below the permissible limit, but $30 \%$ of the locations have noise levels above $50 \mathrm{~dB}(\mathrm{~A})$ and are close to permissible limits.

Similarly, the evaluated $L_{d n}$ values for the mining zone vary from 82.2 to $116.9 \mathrm{~dB}(\mathrm{~A})$. The sensitive zones like S1, S4, S11, S12, and S16 are highly influenced due to mining noise originated from the M1, M6,
M11, M13, and M14 mines, whereas, the residential zones like R2 and R5 are affected by mining noise levels induced by M6 and M7 mines.

The conclusion emerging from the above discussions is that if observed values are considered then $60 \%$ of locations were exposed to high noise levels. Whereas, if predicted calculations are considered then $48 \%$ locations in the sensitive and residential zone are exposed to high noise levels. Both cases show an alarming situation for human settlements in Keonjhar unless the 
expansion of mines and other allied industries is not controlled.

\subsection{Noise mitigation}

The observed and the predicted data clearly reveal that the residential and silence zones of Joda, Badrasahi, Champua, and Rimuli towns are highly exposed to noise levels, primarily due to heavy transportation. The mitigation measures are required to regulate these noise levels to avoid any adverse health effects on the population living in the highly noise exposed zones. The traffic flow relocation plan, such as the construction of the bypass highway away from this area for the transportation of extracted minerals could be a useful mitigation measure to regulate the noise levels in the study area. Assuming the strategy of traffic flow relocation, the $L_{\mathrm{dn}}$ predicted noise couture map of the survey area is regenerated by nullifying the noise levels contribution of heavy vehicles on existing highways and haulage roads which show significant decrease in noise levels from $0-5.3 \mathrm{~dB}(\mathrm{~A})$ as illustrated in Fig. 6. In addition, with the implementation of mentioned noise control approach, there is a possibility of further decrease in the overall noise level in the study area. The traffic congestion on the existing highways and the haulage road is expected to be reduced and subsequently the noise generated due to honking will come down by 3-5 dB(A) (VIJAY et al., 2015). Thus, with this mitigation measure, the anticipated overall noise levels in the study area are within the permissible limits of CPCB and EPA as well.

\subsection{Result validation}

Table 5 shows the correlation between observed $L_{\text {Aeq, } 1 \mathrm{hr}}$ and predicted noise levels. The mean difference between measured and predicted noise descriptors $L_{\mathrm{d}}, L_{\mathrm{n}}$, and $L_{\mathrm{dn}}$ was found to be $6.1,7.2$, and $5.1 \mathrm{~dB}(\mathrm{~A})$, respectively, which is considered an acceptable range.

The average noise recorded in residential regions at six locations close to these zones varies from 45.7 to $56.4 \mathrm{~dB}(\mathrm{~A})$ and 35.5 to $49.5 \mathrm{~dB}(\mathrm{~A})$ during the day and night intervals. The higher noise level was recorded at R1, R3, and R4 locations in the day time and R1, $\mathrm{R} 2, \mathrm{R} 4$, and R5 locations during the night time due to the heavy vehicular movement through this area, later it connects to the mining areas which are exceeding prescribed limits of CPCB. At the same time the minimum and maximum evaluated $L_{\mathrm{dn}}$ levels are 33.9 to $47.2 \mathrm{~dB}(\mathrm{~A})$, which is below the EPA limits for all locations.

Furthermore, the study area was also categorised for different sensitive zones comprising educational institutions, courts, spiritual and health organizations (like hospitals, clinics, etc.) The noise levels recorded at seventeen different silence places ranged from 43.2 to $63.2 \mathrm{~dB}(\mathrm{~A}) ; 32.4$ to $53.4 \mathrm{~dB}(\mathrm{~A})$ throughout the the day and night. The highest noise levels, obtained at 11 locations during the day hours and at 9 locations during the night hours, exceed the permissible limit prescribed by $\mathrm{CPCB}$. The maximum and minimum $L_{\mathrm{dn}}$ levels are 32.7 to $51.2 \mathrm{~dB}(\mathrm{~A})$, which exceeds the norm for two locations (S1 and S16) as per EPA standards.

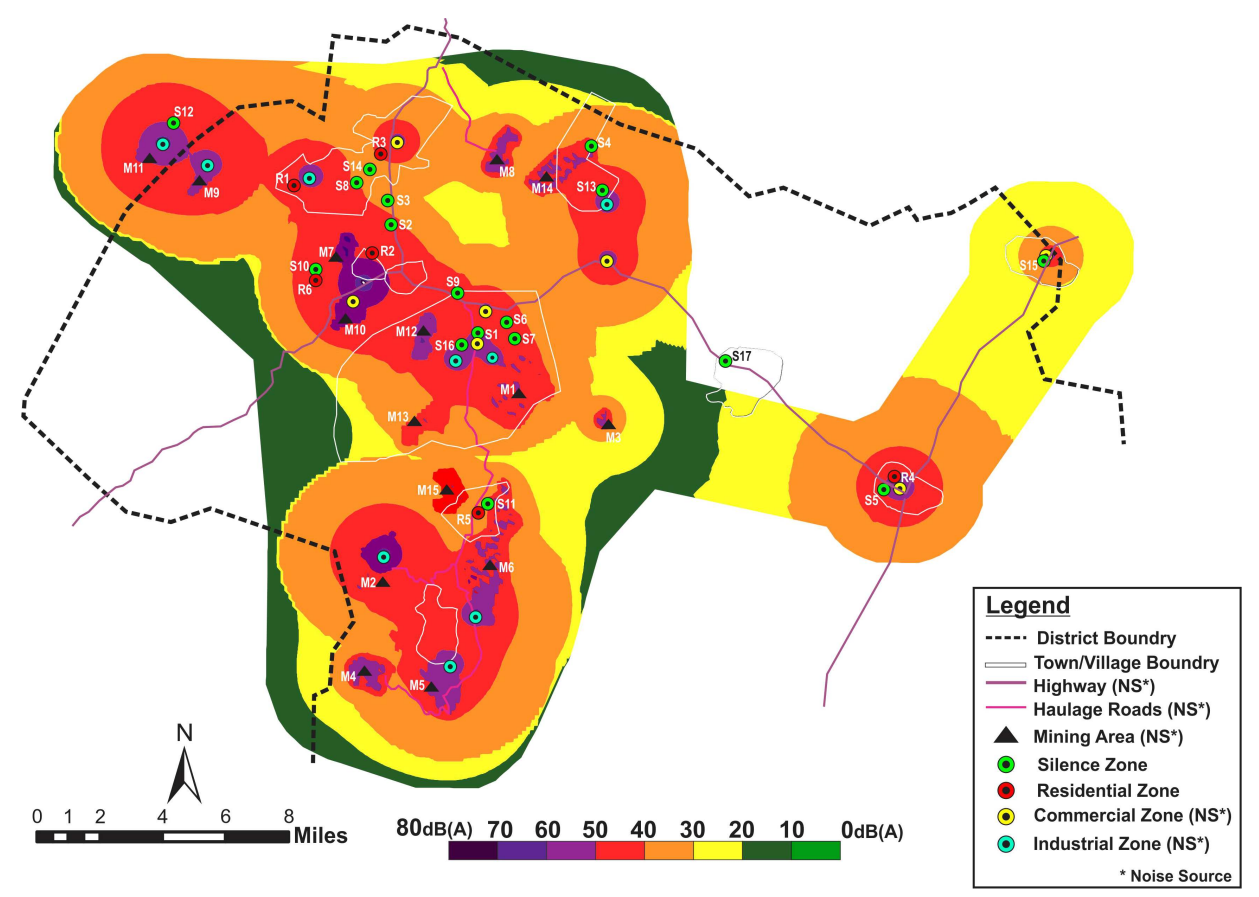

Fig. 6. Noise contour map of predicted noise levels of $L_{\mathrm{dn}}$ assuming mitigation criteria. 
Table 5. Observed and computed noise descriptors for residential and sensitive zones.

\begin{tabular}{|c|c|c|c|c|c|c|c|}
\hline \multirow[b]{2}{*}{ Zones } & \multirow[b]{2}{*}{$\begin{array}{l}\text { Location ID } \\
\text { in map }\end{array}$} & \multicolumn{2}{|c|}{ Day $(6$ am - $10 \mathrm{pm})$} & \multicolumn{2}{|c|}{ Night $(10 \mathrm{pm}-6$ am $)$} & \multicolumn{2}{|c|}{ Day-Night (24 hrs) } \\
\hline & & $\begin{array}{c}\text { Observed } \\
L_{\mathrm{d}, 1 \mathrm{hr}}\end{array}$ & $\begin{array}{c}\text { Predicted } \\
L_{\mathrm{d}} \\
\end{array}$ & $\begin{array}{c}\text { Observed } \\
L_{\mathrm{n}, 1 \mathrm{hr}}\end{array}$ & $\begin{array}{c}\text { Predicted } \\
L_{\mathrm{n}} \\
\end{array}$ & $\begin{array}{c}\text { Calculated } \\
L_{\mathrm{dn}} \\
\end{array}$ & $\begin{array}{c}\text { Predicted } \\
L_{\mathrm{dn}} \\
\end{array}$ \\
\hline \multirow{6}{*}{$\begin{array}{l}\text { Residential } \\
\text { zone }\end{array}$} & $\mathrm{R} 1$ & 55.8 & 48.5 & 49.5 & 43.7 & 47.2 & 49.5 \\
\hline & $\mathrm{R} 2$ & 52.6 & 48.1 & 48.9 & 37.9 & 46.0 & 47.9 \\
\hline & R3 & 55.1 & 46.8 & 39.4 & 28.9 & 42.3 & 45.3 \\
\hline & $\mathrm{R} 4$ & 56.4 & 54.3 & 48.3 & 13.7 & 46.7 & 52.5 \\
\hline & R5 & 45.7 & 42.5 & 47.2 & 34.6 & 43.7 & 42.1 \\
\hline & R6 & 46.8 & 42.8 & 30.5 & 23.9 & 33.9 & 41.7 \\
\hline \multirow{17}{*}{$\begin{array}{l}\text { Sensitive } \\
\text { zone }\end{array}$} & S1 & 62.2 & 57.6 & 46.3 & 42.6 & 49.4 & 56.5 \\
\hline & $\mathrm{S} 2$ & 55.7 & 40.9 & 35.4 & 27.3 & 42.3 & 40.2 \\
\hline & S3 & 47.5 & 39.9 & 42.5 & 26.7 & 39.9 & 39.3 \\
\hline & $\mathrm{S} 4$ & 56.2 & 48.6 & 46.2 & 43.2 & 45.4 & 50.7 \\
\hline & S5 & 59.3 & 55.6 & 43.1 & 35.8 & 46.4 & 54.0 \\
\hline & S6 & 51.8 & 47.7 & 39.7 & 38.1 & 40.1 & 47.7 \\
\hline & S7 & 55.2 & 48.9 & 45.7 & 40.1 & 44.7 & 49.3 \\
\hline & S8 & 45.7 & 40.6 & 39.3 & 33.7 & 37.1 & 41.2 \\
\hline & S9 & 46.1 & 44.9 & 32.4 & 34.9 & 33.8 & 44.9 \\
\hline & $\mathrm{S} 10$ & 43.2 & 42.5 & 33.7 & 28.3 & 32.7 & 41.6 \\
\hline & S11 & 45.6 & 42.5 & 39.1 & 38.5 & 36.9 & 45.5 \\
\hline & $\mathrm{S} 12$ & 58.1 & 50 & 45.1 & 43.2 & 46.1 & 53.2 \\
\hline & $\mathrm{S} 13$ & 57.8 & 48.5 & 42.6 & 42.8 & 45.1 & 50.5 \\
\hline & $\mathrm{S} 14$ & 56.7 & 41.4 & 38.4 & 31.2 & 43.5 & 40.9 \\
\hline & $\mathrm{S} 15$ & 56.1 & 51.2 & 34.6 & 30.5 & 42.6 & 49.5 \\
\hline & S16 & 59.8 & 55.9 & 53.4 & 47.6 & 51.2 & 56.2 \\
\hline & $\mathrm{S} 17$ & 46.8 & 37.2 & 45.9 & 35.2 & 42.6 & 42.5 \\
\hline
\end{tabular}

Figure 7 shows the best-fit lines generated between observed and predicted values that give correlation coefficients $R^{2}$ as 0.5242 for $L_{\mathrm{dn}}$. Also, for the day time it shows $R^{2}$ of 0.605 , and 0.217 for the night time at residential and sensitive zones.

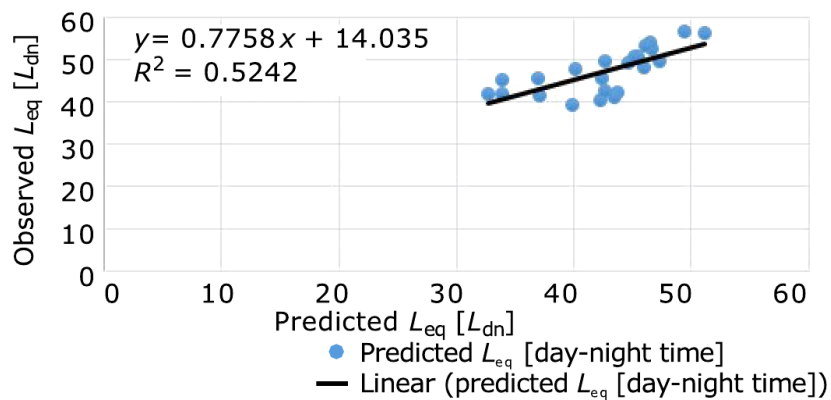

Fig. 7. Correlation between observed and predicted $L_{\text {Aeq, }} T$ of residential and sensitive zones for $L_{\mathrm{dn}}$.

\section{Conclusion}

The processed data show that the noise levels obtained in residential and sensitive zones are exceeding the limits set by CPCB and these zones are pro- foundly affected. The day and night time $L_{\text {Aeq, } T}$ levels ranged between $43.2-62.2 \mathrm{~dB}(\mathrm{~A})$ and $30.5-53.4 \mathrm{~dB}(\mathrm{~A})$, respectively, whereas, the average $L_{\mathrm{dn}}$ values ranged between 32.7 and $51.2 \mathrm{~dB}(\mathrm{~A})$. The $L_{\text {Aeq, } T}$ levels are surpassing the permissible limits at 3 locations in the day time and 4 locations in the night time for the residential zone, whereas, for sensitive area it is true for 11 locations in the day time and at 9 locations in the night time. However, the $L_{\mathrm{dn}}$ levels computed for these zones are within the permissible limits of the EPA, except for two places in the silent zone. From the value of $R^{2}$, it can be concluded that the observed and predicted $L_{\text {Aeq, } T}$ are significantly closer to each other. It is also evident that annoying noise instigated from various sources is affecting the human dwellings and sensitive establishments.

Furthermore, the contour maps specifying the existing noise scenario also illustrate that these two zones are under the influence of high noise levels in more than half of the locations due to mining and road traffic noise. Hence, there is a need to control noise levels in the areas like Joda, Badrasahi, Champua, and Rimuli that are highly exposed to noise. However, the noise contour map forecasting the noise scenario assuming 
the mitigation measure proposed in this study shows a substantial reduction in the noise levels at most of the locations by $0-5.3 \mathrm{~dB}(\mathrm{~A})$. This proves to be an effective control strategy to condense the unnecessary noise levels in residential as well as in silence zones. The results shown by this approach are very promising and show a significant noise reduction in the study area.

Finally, to mitigate the noise pollution level in a district like Keonjhar, which is surrounded by a plethora of mines and industries, such noise maps become an initial document to identify the noise-affected regions. Such maps raise awareness to provide an effective documentation for town planners to execute noise remedial measures. It will also help to plan the infrastructure of the city and will play a crucial part in it. However, the growing economic activities and increasing daily demand of the market will put a major impact on the environment as well as on the health of every species. The noise control policies have to be implemented to avoid the negative effect on the urban or rural population living in the proximity to the mines.

\section{Acknowledgments}

We would like to express our deep gratitude towards CSIR-National Environmental Engineering Research Institute, Nagpur, India as a source of support. Also, to the anonymous reviewers for their valuable suggestions and comments improve the content, quality, and presentation of this paper.

\section{References}

1. Banerjee D., Chakraborty S.K., Bhattacharyya S., Gangopadhyay A. (2009), Appraisal and mapping the spatial-temporal distribution of urban road traffic noise, International Journal of Environmental Science and Technology, 6, 2, 325-335.

2. BARron R.F. (2002), Industrial noise control and acoustics, CRC Press.

3. Bauer E.R., Kohler J.L. (2000), Cross-sectional survey of noise exposure in the mining industry, Proceedings of the 31st Annual Institute of Mining Health, Safety and Research, pp. 17-31, Blacksburg, Virginia, USA.

4. Central Pollution Control Board (2010), Pollution Control Acts, Rules and Notifications Issued Thereunder, from http://www.cpcb.nic.in/NewItem_19_PollutionControlLaw.pdf.

5. Doygun H., Gurun D.K. (2007), Analyzing and mapping spatial and temporal dynamics of urban traffic noise pollution: A case study in Kahramanmaras,
Turkey, Environmental Monitoring and Assessment, 142, 1-3, 65-72.

6. Environmental Protection Agency (EPA 1974), Information on Levels of Environmental Noise Requisite to Protect Public Health and Welfare with an Adequate Margin of Safety, 550/9-74-004, from https://www.rosemonteis.us/files/references/usepa1974.pdf.

7. Garg N., Saxena T.K., Maji S. (2015), Long-term versus short-term noise monitoring: Strategies and implications in India, Noise Control Engineering Journal, 63, 1, 26-35.

8. Kalaiselvi R., Ramachandraiah A. (2010), Environmental noise mapping study for heterogeneous traffic conditions, Proceedings of 20th International Congress on Acoustics, ICA, pp. 23-27, Sydney, Australia.

9. Kerketta S., Gartia G., Bagh S. (2013), Noise Levels of Heavy Earth Moving Machineries in a Chromite Mining Complex of Odisha, India: An Assessment and Analysis, Indian Journal of Applied Research, 3, 6, 5-13.

10. Kim H.C., JeOng J.H., JANG S.I., Kim H.M. (2008), An analysis of effect on road traffic noise reduction substitute through traffic management improved, The Journal of the Acoustical Society of Korea, 27, 8, 403-410.

11. Murthy A.A., RaO G.Y. (2006), "VASUNDHA$R A "$ - Status paper on mining leases in Orissa, from http://admin.indiaenvironmentportal.org.in/files/mining\%20leases\%20in\%20orissa.pdf.

12. Odisha Economic Survey 2014-15 (OES, 201415), from www.odisha.gov.in/pc/Download/Economic_Survey_2014-15.pdf.

13. Optimus Green Sound Level Meters Specifications (CR, 2016), from http://www.cirrusresearch.co.uk/products/sound-level-meters/.

14. Prascevic M.R., Mihajlov D.I., Cvetkovic D.S. (2014), Measurement and evaluation of the environmental noise levels in the urban areas of the city of Nis (Serbia), Environmental monitoring and assessment, 186, 2, 1157-1165.

15. Predictor-LimA Software Portfolio (LimA, 2016), from http://www.bksv.com/servicecalibration/support/downloads/7810predictor/firmware\%20installation\%20program.aspx.

16. Vijay R., Sharma A., Chakrabarti T., Gupta R. (2015), Assessment of honking impact on traffic noise in urban traffic environment of Nagpur, India, Journal of Environmental Health Science and Engineering, 13, 1, 1-9.

17. Whitaker J.C., Benson B. (2001), Standard Handbook of Audio and Radio Engineering, 2nd ed., McGraw-Hill Education, New York. 